\title{
Centralisatie van de prostaatkankerzorg
}

\author{
Henk G. van der Poel ${ }^{1}$
}

Published online: 4 September 2017

(c) The Author(s) 2017. This article is an open access publication.

Samenvatting In de literatuur is de laatste jaren veel geschreven over het voordeel van centralisatie van kankerzorg in het algemeen en prostaatkankerzorg in het bijzonder. In Nederland heeft de centralisatie van prostaatkankerzorg (nog) geen grote vlucht genomen. Toch is er wel degelijk sprake van prostaatkanker-zorgbundeling in specifieke ziekenhuizen. Uit data van de prostaatkankerregistratie van de NVU blijkt dat er op dit moment meer ziekenhuizen zijn die geen dan die wel een radicale prostatectomie uitvoeren. Op de website www.nvukwaliteit.nl voeren jaarlijks rond de 30 ziekenhuizen de gegevens in van hun patiënten die een prostatectomie ondergingen.

Trefwoorden prostaatkanker $\cdot$ prostatectomie . centralisatie

\section{Prostate cancer care centralisation}

Abstract Prostate cancer care centralisation may lead to better outcome as data from several clinical studies showed. In the Netherlands, the National Prostatectomie Registry provides information on clinical characteristics and pathological outcome of men that underwent prostatectomy for prostate cancer. Data from this and other registries are expected to help improve surgical outcome.

Keywords prostate cancer $\cdot$ prostatectomie $\cdot$ centralisation

dr. Henk G. van der Poel

h.vd.poel@nki.nl

1 afdeling Urologie, Nederlands Kanker Instituut, Amsterdam, Nederland

\section{Wie gingen ons voor?}

Over 2016 waren data van 2028 prostatectomieën uit 30 ziekenhuizen beschikbaar voor analyse. Alvorens hierop in te gaan, eerst een beknopt overzicht van de recente literatuur omtrent de centralisatie van de prostatectomiezorg. In het Verenigd Koninkrijk (VK) besloot de National Health Service (NHS) in 2002, na het verschijnen van hun rapport 'Improving outcomes in urological cancers', om het aantal uit te voeren prostatectomieën op jaarbasis te stellen op 50 per kliniek. Hierdoor halveerde in 12 jaar tijd het aantal ziekenhuizen in het VK dat de prostatectomie uitvoerde en zette de trend tot verbetering van de tienjaarsoverleving van prostaatkanker gestaag door.

Data uit de Londense regio, waar negen klinieken besloten om hun prostatectomieën te clusteren, toonden aan dat, na de introductie van een Quality Assurance Program (QAP) het aantal complicaties halveerde en de postoperatieve continentie en erectiele functie verbeterden [1]. Een belangrijk onderdeel van dit QAP is de postoperatieve evaluatie van de videobeelden van de ingreep. Door deze methode lijkt een proces op gang gekomen van continue verbetering. Of dit ook zonder centralisatie mogelijk was geweest, is uiteraard een punt van discussie, maar het feit dat het QAP pas werd geïntroduceerd toen het aantal ingrepen groeide, geeft wel aan dat motivatie om te verbeteren en volumegroei, hand in hand gingen.

\section{Hoe gaat het in de praktijk?}

In veel landen zijn nationale registratiedata voorhanden die onderzoek naar de invloed van concentratie van zorg en uitkomsten mogelijk maken. In een registratie van de Nationalwide Inpatient Sample (NIS) werden de data van 
140.671 patiënten die een prostatectomie ondergingen tussen 2009 en 2011 retrospectief geïncludeerd en geanalyseerd [2]. Uit deze analyse bleek dat vanaf een jaarlijks aantal van 100 prostatectomieën per kliniek, een afname te zien was in complicaties, bloedtransfusies, verlengde opname en kosten. Om dit in de Nederlandse registratiedata te analyseren, is over het jaar 2016 gekeken naar een aantal factoren in klinieken die minder dan 100 ingrepen invoerden en klinieken die er meer deden. Opvallend is dat, in aantallen patiënten, de groepen met 988 en 974 mannen vergelijkbaar waren. Ook was er geen verschil in Roach$\mathrm{N}+$-risicoscore en prostaatvolume. In vergelijking met de NIS-data was er geen verschil in opnameduur tussen ziekenhuizen die minder en die meer dan 100 prostatectomieën per jaar deden. Wel liet de Nederlandse registratie zien dat mannen die waren geopereerd in klinieken die in 2016 minder dan 100 ingrepen in de registratie invoerden, significant meer bloedverlies hadden tijdens een significant langere operatie. Bovendien was het overall positief snijvlakpercentage in de hoogvolumeklinieken $6 \%$ lager dan in de klinieken met een lager volume. Dit verschil was $5 \%$ voor de pT2-tumoren en $7 \%$ voor de pT3-tumoren en in beide gevallen significant met een $p<0,02$.

\section{Hoe gaan we verder?}

De aandacht die er is voor centralisatie is op zich al winst. Laten we gezamenlijk de data kritisch tegen het licht houden. Goede registraties opzetten, patiënten met regelmaat postoperatief gestandaardiseerde vragenlijsten laten invul- len, onze ingrepen opnemen en terugkijken waar nodig, zijn slechts een paar mogelijkheden om de kwaliteit verder te verbeteren. Pas als iedereen hiertoe bereid is en het ook werkelijk doet, ben ik bereid om de centralisatiegedachte te laten varen en de huidige situatie van veelal decentraal behandelen te accepteren. De NVU biedt een tweetal platformen voor de hier beschreven mogelijkheden: www. nvukwaliteit.nl en www.levenskwaliteitprostaatkanker.nl. Iedereen kan dus, kosteloos, meteen met de evaluatie aan de slag.

Open Access This article is distributed under the terms of the Creative Commons Attribution 4.0 International License (http:// creativecommons.org/licenses/by/4.0/), which permits unrestricted use, distribution, and reproduction in any medium, provided you give appropriate credit to the original author(s) and the source, provide a link to the Creative Commons license, and indicate if changes were made.

\section{Literatuur}

1. Cathcart P, Sridhara A, Ramachandran N, et al. Achieving quality assurance of prostate cancer surgery during reorganisation of cancer services. Eur Urol. 2015;68(1):22-9.

2. Gershman B, Meier SK, Jeffery MM, et al. Redefining and contextualizing the hospital volume-outcome relationship for robot-assisted radical prostatectomy: implications for centralization of care. J Urol. 2017;198(1):92-9.

dr. Henk G. van der Poel uroloog 